\title{
INVESTIGATION OF SURFACE MACROSCOPIC RESIDUAL STRESSES OF CUTTING CERAMICS AFTER MECHANICAL MACHINING
}

\author{
Jakub NĚmeČeK*， Jiří Čapek， Nikolaj Ganev， Kamil KolaŘíK \\ Department of Solid State Engineering, Faculty of Nuclear Science and Physical Engineering, Czech Technical \\ University in Prague \\ * corresponding author: jakub.nemecek@fjfi.cvut.cz
}

\begin{abstract}
Currently, the extensive research in the field of cutting ceramics is conducted and there are efforts to replace cemented carbides by these materials. However, the problem is to improve the production of ideal compact samples. Therefore, the influence of mechanical machining technologies on the values of macroscopic residual stresses was investigated by X-ray diffraction. The resulting values were discussed depending on machining parameters and surface structure of the studied samples.
\end{abstract}

KEYWORDS: Cutting ceramics; X-ray diffraction; Residual stress; Machining technology.

\section{INTRODUCTION}

A development of cutting ceramics has begun at the beginning of $20 t h$ century. Nowadays, there is an attempt to optimize the production process and machining parameters depending on the real structure of ceramic tiles [1-4]. In cooperation with Moscow State Technological University Stankin (MSTU Stankin), which provides preparation of samples, the macroscopic residual stresses were analysed by X-ray diffraction. Analysed samples were prepared from different materials such as trigonal $\mathrm{Al}_{2} \mathrm{O}_{3}$ (samples 2.x), hexagonal $\mathrm{Si}_{3} \mathrm{~N}_{4}$ (samples 3.x), hexagonal SiC (samples 4.x), and tetragonal $\mathrm{ZrO}_{2}$ (samples 5.x). They were finished with different mechanical surface treatments, specifically grinding by diamond disc (samples x.1-x.3) and air abrasive treatment (AAT, samples x.9-x.11), see Table 1 and 2. Samples of first series (1.x) were analysed in [5].

Production of samples differed for individual materials. Samples of $\mathrm{Al}_{2} \mathrm{O}_{3}, \mathrm{SiC}$ and $\mathrm{ZrO}_{2}$ were made by so called standard sintering, when they were pressed at low temperature and then put into a furnace, where the bonds in material were created. Samples of nitride ceramics were made by cold sintering, but they were put into compressible ampoules which the hydrostatic pressure exerted during the sintering process. This has resulted in high material densities, see [6].

\begin{tabular}{cc}
\hline Sample & Material \\
\hline $2 . \mathrm{x}$ & $\mathrm{Al}_{2} \mathrm{O}_{3}$ \\
$3 . \mathrm{x}$ & $\mathrm{Si}_{3} \mathrm{~N}_{4}$ \\
$4 . \mathrm{x}$ & $\mathrm{SiC}$ \\
$5 . \mathrm{x}$ & $\mathrm{ZrO}_{2}$ \\
\hline
\end{tabular}

TABLE 1. Materials of individual series of samples.

\begin{tabular}{cc}
\hline Sample & Technology \\
\hline x.1-x.3 & Grinding by diamond disc \\
x.9-x.11 & Air abrasive treatment \\
\hline
\end{tabular}

TABLE 2. Machining technologies of individual series of samples.

\section{EXPERIMENT}

The influence of machining parameters on the surface values of macroscopic residual stresses was studied by X-ray diffraction. For grinding by diamond disc, the impact of transverse displacement on the lift $F_{d}$ was studied, and for the AAT, where the sample rotated, the influence of loading time $\mathrm{T}$ was analysed (see Tables 3 and 4). Values of residual stresses were determined in two orthogonal directions L (direction of grinding) and $\mathrm{T}$ (direction of transverse displacement). The tensometric analysis of macroscopic residual stresses had different parameters for individual series of samples. For $\mathrm{Al}_{2} \mathrm{O}_{3}$ diffraction line $\{0210\}$ was analysed by manganese anode on diffraction angle $2 \Theta=146^{\circ}$ and X-ray diffraction constants $s_{1}=-0.61 \mathrm{TPa}^{-1}, \frac{1}{2} s_{2}=3.18 \mathrm{TPa}^{-1}$, for $\mathrm{Si}_{3} \mathrm{~N}_{4}$ diffraction line $\{201\}$ by chromium anode on diffraction angle $2 \Theta=63^{\circ}$ in $\psi$-geometry and X-ray diffraction constants $s_{1}=-0.87 \mathrm{TPa}^{-1}, \frac{1}{2} s_{2}=3.87 \mathrm{TPa}^{-1}$, for $\mathrm{SiC}$ diffraction line $\{028\}$ by manganese anode on diffraction angle $2 \Theta=149.5^{\circ}$ and X-ray diffraction constants $s_{1}=-0.41 \mathrm{TPa}^{-1}, \frac{1}{2} s_{2}=2.74 \mathrm{TPa}^{-1}$ and for $\mathrm{ZrO}_{2}$ diffraction line $\{220\}$ by chromium anode on diffraction angle $2 \Theta=128^{\circ}$ and X-ray diffraction constants $s_{1}=-1.45 \mathrm{TPa}^{-1}, \frac{1}{2} s_{2}=6.42 \mathrm{TPa}^{-1}$. For more details see [6].

\section{RESUlt AND DisCUSSION}

At first, all samples were machined by diamond disc and some of them subsequently machined by air abra- 


\begin{tabular}{cc}
\hline Sample & $\begin{array}{c}F_{d}, \\
{[\mathrm{~mm} / \text { displ. }]}\end{array}$ \\
\hline $\mathrm{x} .1$ & 0.5 \\
$\mathrm{x} .2$ & 1.0 \\
$\mathrm{x} .3$ & 1.5 \\
\hline
\end{tabular}

TABLE 3. Parameters of grinding by diamond disc.

\begin{tabular}{cc}
\hline \multirow{2}{*}{ Sample } & $\begin{array}{c}\mathrm{T}, \\
{[\mathrm{s}]}\end{array}$ \\
\hline $\mathrm{x} .9$ & 15 \\
$\mathrm{x} .10$ & 30 \\
$\mathrm{x} .11$ & 60 \\
\hline
\end{tabular}

TABLE 4. Parameters of AAT.

sive treatment. Depending on the structure, various effects of machining technology on the surface structure were found.

For trigonal $\mathrm{Al}_{2} \mathrm{O}_{3}$, the values of residual stresses have expecting character, i.e. while after grinding by diamond disc in direction $\mathrm{L}$, values of compressive residual stresses decrease with increasing $F_{d}$, in direction $\mathrm{T}$, the compressive residual stresses increase (see Figure 1). This effect is caused by moving the cutting tool in the L direction, when the so-called stretching of the subsurface areas occurs due to the mechanical interaction of the cutter blades with the material. In the $\mathrm{T}$ direction, the higher feed rate leads to higher stresses.

In the case of air abrasive machining, it is evident that with the increasing time of machining, the values of the compressive residual stresses increase while the isotropy of the values of the macroscopic residual stresses in the $\mathrm{L}$ and $\mathrm{T}$ directions are increased. This is caused by the rotational movement of the sample during machining. With longer time of machining the depth of the infuenced surface layer of material increases. To prove that is necessary to determine precisely the depth gradient of macroscopic residual stresses by forceless polishing.

In the case of $\mathrm{Si}_{3} \mathrm{~N}_{4}$ (see Figure 2), the residual stresses were analysed by different experimental geometry due to overlap of diffraction lines with diffraction angles above $110^{\circ} 2 \Theta$. It means the resulting values of residual stresses are from thinner surface (ca. $4 \times$ thinner). An accuracy of determination of position $2 \Theta$ is about $8,5 \times$ smaller than for diffraction lines with higher angles $2 \Theta$. However, the relative dependence for determining the effect of mechanical machining on surface residual stresses is indicative. After diamond wheel grinding, the compressive residual stresses increase in the both directions with increasing $F_{d}$. This is caused by hexagonal close packed structure of $\mathrm{Si}_{3} \mathrm{~N}_{4}$ and its resistance to machining. As it has been shown in [7, machining materials with the hexagonal close packed lattice can cause an increase of compressive residual stresses in the grinding direction. This effect

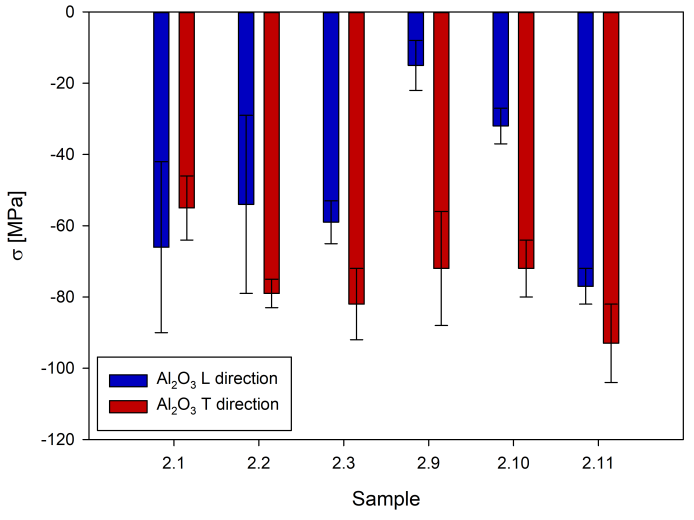

FigURE 1. Values of macroscopic residual stresses after grinding by diamond disc (samples x.1-x.3) and AAT (samples x.9-x.11) of $\mathrm{Al}_{2} \mathrm{O}_{3}$.

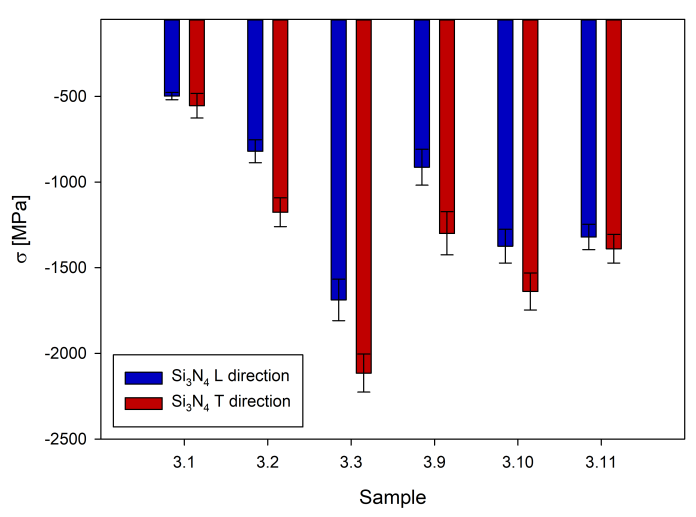

FiguRE 2. Values of macroscopic residual stresses after grinding by diamond disc (samples x.1-x.3) and AAT (samples x.9-x.11) of $\mathrm{Si}_{3} \mathrm{~N}_{4}$.

is induced by the reaction of the structure to a force which resists plastic deformation.

After air abrasive treatment of $\mathrm{Si}_{3} \mathrm{~N}_{4}$ samples, the effect of the previous machining technology can be seen. At a short machining time, the macroscopic residual stresses have a relatively large anisotropy and, with increasing machining time, this anisotropy disappears. At the same time, it can be seen that with the machining time, the values of the surface compressive residual stresses increase, which is again caused by the hexagonal structure. Compressive stresses dropped for sample 3.11 probably by sliding along the grain boundaries (there was an increase in crystallite size, see [8]).

For hexagonal $\mathrm{SiC}$, it can be seen that in case of grinding with a diamond disc in the direction of grinding (direction $\mathrm{L}$ ), the values of the compressive residual stresses increase and in the direction perpendicular (direction $\mathrm{T}$ ), the tensile residual stresses decrease. This dependence is inconsistent with expectations, since in general grinding causes tensile stresses in the direction of grinding and in the perpendicular direction the compressive residual stresses. It is caused 


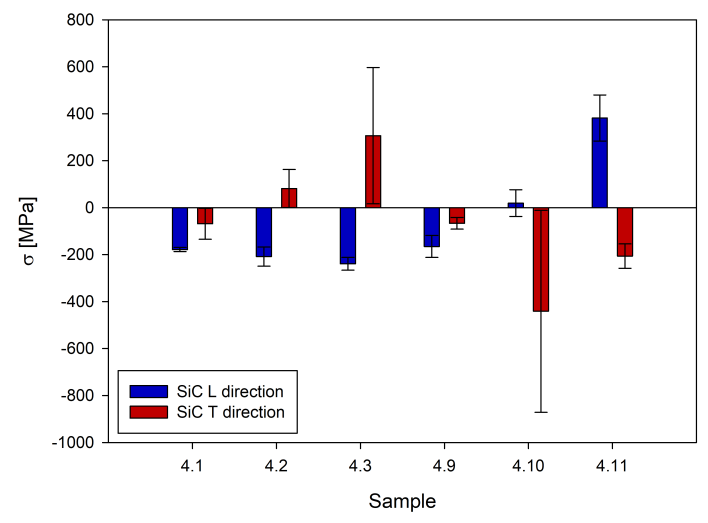

FiguRE 3. Values of macroscopic residual stresses after grinding by diamond disc (samples x.1-x.3) and AAT (samples x.9-x.11) of SiC.

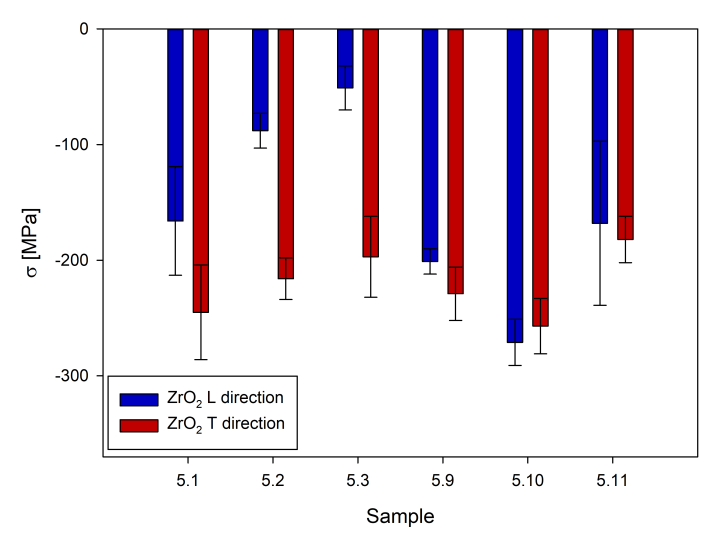

Figure 4. Values of macroscopic residual stresses after grinding by diamond disc (samples x.1-x.3) and AAT (samples x.9-x.11) of $\mathrm{ZrO}_{2}$.

again by hexagonal close packed structure of $\mathrm{SiC}$, see [7.

Values of macroscopic residual stresses after air abrasive treatment of $\mathrm{SiC}$ samples show very high experimental errors. These are due to the large dimensions of crystallites. However, it is evident that in the $\mathrm{L}$ direction, the values of the compressive residual stresses decrease, even tensile stresses increase, and in the $\mathrm{T}$ direction the compressive stresses on the contrary increase. This is caused again by the influence of the hexagonal lattice and its resistance to plastic deformation (see Figure 3).

After grinding by diamond disc of $\mathrm{ZrO}_{2}$, it is evident that the values of the compressive macroscopic residual stresses decrease with the increasing $F_{d}$. This is due to the thermal overload of the surface. The thermal conductivity coefficient for $\mathrm{ZrO}_{2}$ is approximately one-tenth compared to other studied materials $\left(\lambda=2,7 \mathrm{Wm}^{-1} \mathrm{~K}^{-1}\right.$ for $\mathrm{ZrO}_{2}$, other ceramics have a temperature coefficient $\lambda=30 \mathrm{Wm}^{-1} \mathrm{~K}^{-1}$ and more).

For air abrasive treatment, it is obvious that due to the rotational movement of the $\mathrm{ZrO}_{2}$ samples, an isotropic distribution of macroscopic residual stresses

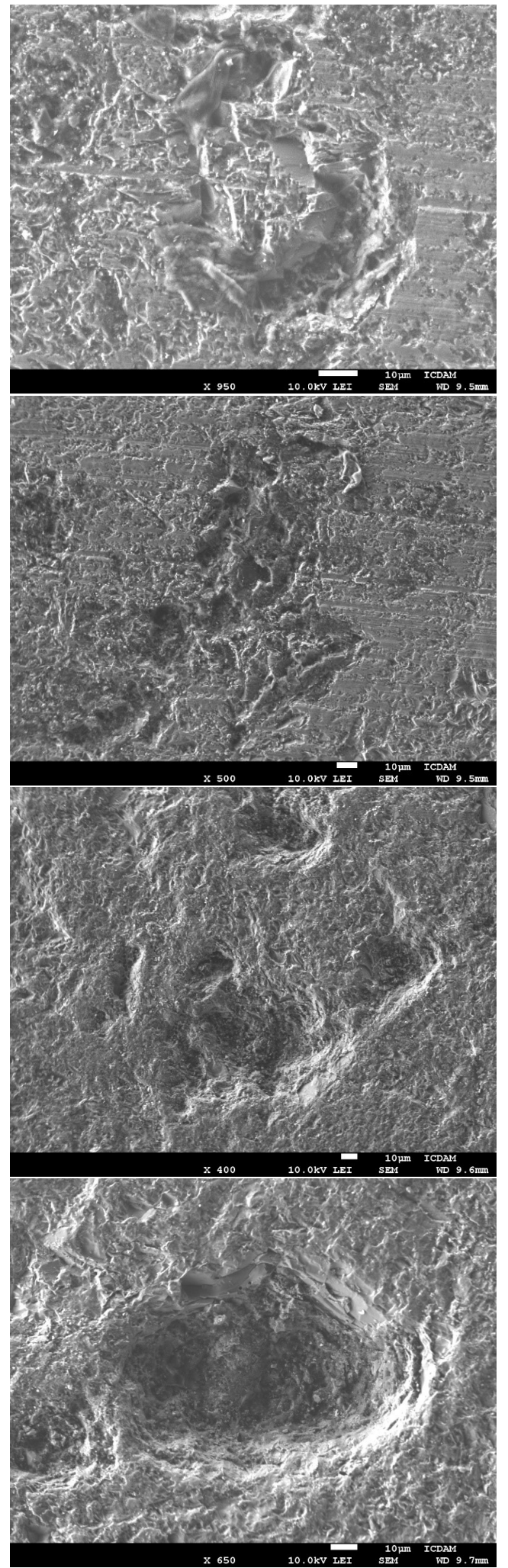

Figure 5. Surface defects of $\mathrm{SiC}$ cutting ceramic after grinding by diamond disc $(5 \mathrm{a}, 5 \mathrm{~b})$ and AAT $(5 \mathrm{c}, 5 \mathrm{~d})$.

has occurred, the values in the $\mathrm{L}$ and $\mathrm{T}$ directions are same within the error (see Figure 4).

For samples from $\mathrm{SiC}$ the analysis of surface with SEM was made. The purpose was to investigate a presence of cracks, which may be caused by large tensile residual stresses. However, it is evident from 
Figure 5 that no cracks were found. But the images show, alongside smooth cutting traces, surface defects caused by grinding, such as various holes or ejected grains.

The morphology of surface is significantly changed since the cutting traces of diamond wheel disappeared and instead can be seen deep craters after the impact of individual grains of abrasive.

\section{Conclusions}

The analysis of macroscopic residual stresses of surfaces of four different ceramic materials was performed by X-ray diffraction and the effect of mechanical machining on the surface structure was determined. Different reactions of hexagonal structures on mechanical machining were observed. It was found that $\mathrm{ZrO}_{2}$ due to poor thermal conductivity had to be machined at lower speeds or pressures, otherwise the heat load of the structure and the tensile residual stresses would increase.

\section{ACKNowledGements}

This work was supported by grant Student Grant Competition CTU no. SGS16/246/OHK4/3T/14 and Grant Agency of the Czech Republic (no. 14-36566G).

\section{REFERENCES}

[1] A. Humár. Materiály pro řezné nástroje. First printing. MM publishing, 2008.

[2] V. V. Kuzin, et al. Correlation of diamond grinding regimes with $\mathrm{Al}_{2} \mathrm{O}_{3}$-TiC-ceramic surface condition. Refractories and Industrial Ceramics 57(1):520-525, 2017. DOI:https://doi.org/10.1007/s11148-017-0016-0
[3] V. V. Kuzin, et al. Correlation of diamond grinding regimes with sisic-ceramic surface condition. Refractories and Industrial Ceramics 58(2):214-219, 2017. DOI:https://doi.org/10.1007/s11148-017-0108-x

[4] V. V. Kuzin, et al. Correlation of diamond grinding regime with surface condition of ceramic based on zirconium dioxide. Refractories and Industrial Ceramics $\mathbf{5 7}(1): 625-630,2017$. DOI:https://doi.org/10.1007/s11148-017-0035-x

[5] J. Němeček, K. Kolařík, J. Čapek, G. N. Influence of machining technologies on values of residual stresses of oxide cutting ceramics. Acta Polytechnica CTU Proceedings (9):13-18, 2017. DOI:https://doi.org/10.14311/APP.2017.9.0013

[6] J. Němeček. Difrakcní studium vybraných charakteristik řezné keramiky, Prague 2017. Master thesis (Ing.). Czech Technical University in Prague, Faculty of Nuclear Science and Physical Engineering, Department of Solid State Engineering, 2017-06-16.

[7] K. T. Ramesh. Effects of high rates of loading on the deformation behavior and failure mechanisms of hexagonal close-packed metals and alloys. Metallurgical and Materials Transastions A 33:927-935, 2002. DOI:https://doi.org/10.1007/s11661-002-0162-x.

[8] Z. Yin, et al. Friction and wear behaviors of $\mathrm{Al}_{2} \mathrm{O}_{3} /$ TiC micro-nano-composite ceramic sliding against metals and hard materials. Ceramic International 42:1982-1989, 2016. DOI:https://doi.org/10.1016/j.ceramint.2015.10.001. 